\title{
ESTRATÉGIAS EM REDES DE POLÍTICAS E EM ARRANJOS DE GOVERNANÇA MULTINÍVEL: UM OLHAR SOB A PERSPECTIVA DA TEORIA DA PRÁTICA
}

\author{
STRATEGIES IN POLICY NETWORKS AND GOVERNANCE \\ ARRANGEMENTS: A VIEW FROM THE THEORY OF \\ PRACTICE PERSPECTIVE
}

\author{
Mario Procopiuck \\ Pontifícia Universidade Católica do Paraná - PR - Brasil
}

\begin{abstract}
Resumo: O presente artigo tem como objetivo explicitar os fundamentos e utilizar a Teoria da Prática, de Pierre Bourdieu, como meio para melhor compreender a lógica relacional entre agentes, a capacidade de agência e estruturas em contextos de ação estratégica espacialmente situada. Com fundamentos ontológicos e epistemológicos do realismo crítico, são articulados os conceitos de habitus, capital e campo, como meios de explicitação de variáveis constituintes e influenciadoras de ações estruturadas para defesa de interesses sociopolíticos, tendo na compreensão das potencialidades do agente importante fonte explicativa da ação estrategicamente organizada. As conclusões indicam que a Teoria da Prática pode trazer contribuições promissoras para estudos do ciclo de políticas públicas, principalmente por fortalecer abordagens como social network analysis, governança multinível e redes de políticas.
\end{abstract}

Palavras-chave: Teoria da Prática. Estratégias. Agentes sociopolíticos. Redes de políticas. Governança multinível.

Abstract: The object of this article is to explain the fundaments and utilization of the Theory of Practice, by Pierre Bourdieu, as a means to better understand the relational logic among agents, the capacity of agents and the contextual structure of strategic action spatially located. The concepts of habitus, capital and field, with ontological and epistemological fundaments of critical realism are articulated as means to explain several influential constituents of structured actions to defend sociopolitical interests, while considering the potential of agents as important positive sources of strategically organized actions. Conclusions reveal that the Practice of Theory can bring promising contributions to the study of public policies, especially to strengthen approaches such as social network analysis, multilevel governance and policy networks.

Keywords: Theory of Practice. Strategies. Social-political agents. Policy networks. Governance systems.

\section{Introdução}

Em sentido amplo, a capacidade dos governos é, em grande parte, decorrente de influências de variáveis territoriais, dado que os próprios estados podem ser vistos como fenômenos territoriais. Com funções de alocação de recursos e de distribuição e controle legitimado do poder, a busca de equilíbrios regionais por meio de políticas estatais tende a ser espacialmente sensível. Assim, a organização dos aparatos responsáveis por colocar em ação a administração pública, o exercício do poder interno de polícia e de formação de sistemas de defesa externa, a proteção social e de direitos individuais, as estratégias de 
desenvolvimento econômico, dentre outras, são dependentes de relações centrallocal condicionadas por campos de forças que se estruturam de forma complexa a partir da conjunção de variáveis sociopolíticas e espaciais (PAINTER, 2005; SAVAGE, 2011).

Nesses campos complexos institucionalizados e estruturados por organizações inter-relacionadas em multiníveis, por um lado, os indivíduos nelas implexos possuem diferentes capacidades de agir estrategicamente sob influências de variáveis da própria organização e de outras provenientes de contextos mais amplos. Por outro, as organizações resultam da constante construção e reconstrução dos processos influenciados por agentes externos posicionados de forma espaço temporal. A compreensão de como os agentes se comportam em redes organizacionais e a que tipos de influências estão sujeitos transcende, portanto, à dimensão subjetiva. A compreensão mais profunda das ações estratégicas em que são envolvidos requer que sejam considerados em interação com seus pares e, concomitantemente, com o contexto em que desenvolvem suas ações práticas (DJALO; PROCOPIUCK, 2010; PROCOPIUCK, 2013). Agir para além dessa perspectiva sociopolítica requer que, concomitantemente, se reconheça que construções sociais dependem de como os atores estão capacitados para apreender a realidade a partir de diferentes escalas territoriais de redes de governança, considerando múltiplas fontes de conhecimento que permitam vincular a ação aos reflexos práticos sobre diferentes territórios (MICHELINI, 2010; RIVOLIN et al., 2014).

Nesse espaço de investigação teórica, com o presente artigo, explora-se a Teoria da Prática, de Pierre Bourdieu, para explicitar e estabelecer conexões entre variáveis que podem influenciar estratégias de agentes individuais em interação com aquelas que emanam de contextos sociopolíticos, estruturados por sistemas de governança de multinível situados em diferentes espaços e lugares, considerando especialmente a capacidade de agência humana em campos estruturados e permeados reticularmente por relações cooperativas e competitivas, que podem ser pontuais ou continuadas no tempo.

\section{Pressupostos ontológicos e epistemológicos}

A compreensão mais sofisticada de conjunturas relacionais em que se inserem as práticas estratégicas é facilitada pela articulação de abordagens teóricas ontologicamente coerentes, pois permitem que reflexões se situem com maior clareza frente à natureza da realidade social sob discussão. Os esforços analíticos nessa direção procuram explicitar as premissas subjacentes à própria existência do mundo social, à sua representação, às unidades que o compõem e como tudo isso interage em diferentes espaços e lugares (DJALO; PROCOPIUCK, 2010; CAINE, 2013).

Sustentadas em premissas ontológicas surgem, consequentemente, importantes questões epistemológicas. Elas dizem respeito ao que pode ser aceito razoavelmente como conhecimentos válidos - em termos de critérios utilizados para obter sua justificação -, de modo a afastá-los de crenças pautadas no senso 
comum (POTTER, 2000, p. 243; BATES; JENKINS, 2007, p. 57; BLAIKIE, 2007, p. 38-41).

Por tais motivos, a seguir - depois de breves considerações sobre a relação entre estrutura, agência e estratégias como práticas - são definidas bases ontológicas e epistemológicas que permitem posicionar a Teoria da Prática como meio de aprofundar o conhecimento das ações estratégicas em contextos sociopoliticamente organizados.

\subsection{Aplicabilidade da Teoria da Prática para compreensão de práticas estratégicas}

Os fundamentos da Teoria da Prática apresentam compatibilidades importantes com a ontologia realista (NASH, 1999, p. 445; HAMLIN, 2000; POTTER, 2000, p. 229; MUTCH; DELBRIDGE; VENTRESCA, 2006, p. 610). Em relação aos estudos de estratégias organizacionais, embora Bourdieu não tenha se preocupado diretamente com eles, a Teoria da Prática tem bases teórico-empíricas passíveis de recorte pautado por premissas do realismo crítico (MUTCH; DELBRIDGE; VENTRESCA, 2006, p. 610).

A suposição ontológica fundamental no realismo crítico é que o mundo é independente de nossa imaginação sobre ele. $O$ interesse volta-se para a razão, pois a realidade teria existência independente da mente humana e cuja apreensão seria dependente da imanente capacidade humana de reflexão e da razão (BLAIKIE, 2007, p. 15). Não haveria, portanto, meios para se ter acesso direto e não mediado a tal mundo; logo, não faria sentido entrelaçar nossos conceitos sobre mundo com a existência do próprio mundo (MUTCH; DELBRIDGE; VENTRESCA, 2006, p. 611-612).

$\mathrm{Na}$ ontologia realista, a realidade é composta por três níveis ou domínios. O domínio empírico diz respeito ao mundo experimentado pelos sentidos; o domínio atual inclui eventos que podem ou não ser observados; e o domínio real é constituído por processos generativos de eventos. As implicações são que o domínio empírico é superficial, já que abrange somente o que é passível de experimentação; o domínio atualé substancial, pois diz respeito às estruturas e aos poderes do objeto que gera a ação; e o domínio rea/se refere ao que acontece se, e quando, aqueles poderes são ativados, e ao que eles produzem com seus efeitos no mundo fático. No domínio real, considera-se que os objetos da investigação científica existem e atuam independentemente do cientista e de sua atividade. Há, portanto, uma realidade "lá fora" e que está sendo observada (BLAIKIE, 2007, p. 16).

Em termos epistemológicos, o realismo crítico oferece um modelo transformacional da sociedade, com atenção voltada para sua estrutura, vista como relacional. Seus fundamentos têm sustentação na aceitação dos seres humanos como detentores de poderes causais determinantes, de autorreflexividade e de capacidade de decisão intencional (POTTER, 2000, p. 230231). O racionalismo crítico representa, portanto, uma tentativa de síntese entre agência e estrutura (HAMLIN, 2000). 
$\mathrm{Na}$ concepção do realismo crítico, para a ciência ser um empreendimento possível, a realidade deve ser apreendida a partir da consciência coletiva (BLAIKIE, 2007, p. 15), via utilização de mecanismos causais que produzem os estados dos eventos registrados como o "real". Esses mecanismos se constituem em objeto de atenção quanto aos meios necessários para sua identificação e exploração. Entretanto, dado que sempre estarão implexos em contextos relacionais mais amplos, nunca serão absolutos e nem isolados. São mecanismos que funcionam conformados por limites restritivos e, por tal razão, estão sujeitos a interferências de outros mecanismos e fatores com potencial de desconsertar a sua operação. Ainda, mesmo existindo os mecanismos causais, eles podem não ser ativados, ou seus efeitos obscurecidos por tendências de compensação (MUTCH; DELBRIDGE; VENTRESCA, 2006, p. 611-612). Portanto, a identificação de mecanismos causais é importante e indispensável para compreender a ação em contextos sociais, mas não, necessariamente, determinante, per se, para a compreensão de impactos de resultados práticos. Tratam-se, pois, de relações complexas dependentes de intencionalidades e de capacidade de agência conjunturais.

Embora não haja consenso de que represente a única perspectiva interpretativa possível para a Teoria da Prática, o realismo crítico permite representação substantiva de realidades complexas estruturadas, ontologicamente estratificadas em diferentes níveis, e dialeticamente explicadas. A solução metateórica realista pode ser aplicada a problemáticas relacionadas à estrutura social, à capacidade de agência e à própria ação social, tanto em pesquisas teóricas quanto substantivas; mormente quando se utiliza inter-relacionada e dinamicamente os conceitos de habitus, capital e de campo (POTTER, 2000).

$O$ inter-relacionamento entre esses três conceitos nucleares do pensamento de Pierre Bourdieu se constitui em arcabouço mediante o qual escolhas e ações individuais podem, para fins analíticos, ser imbricadas logicamente em processos mais amplos de casualidades estruturais. Exemplo disso são as determinações econômicas encadeadas estruturalmente, mas não de modo linear, entre vários campos, na medida em que, causalmente e de maneira complexa, influenciam o modo como indivíduos atuam e realizam escolhas em diferentes espaços (POTTER, 2000).

\subsection{Lógica relacional e filosofia da ação em práticas estratégicas}

Como estratégia para transcender a oposição artificialmente criada entre estruturas e representações, com a chamada revolução estruturalista, tem sido aplicado com êxito ao mundo social o modo relacional de pensamento da matemática e da física modernas, cuja finalidade é identificar o que é verdadeiro não por meio de substâncias, mas por meio de relações (BOURDIEU, 1989b, p. 15-16). Para os teóricos relacionais, a atividade humana não decorre simplesmente do comportamento do indivíduo, mas é influenciada por todo o conjunto de relações que, de certo modo e em certo grau, o condicionam. Dentre os elementos dinamicamente relacionados, destacam-se o ato, o contexto, o agente, a agência e a intenção (EVERETT, 2002; HEPP, 2006). Dentre esses cinco elementos, para fins 
de análise de estratégias, a intencionalidade teologicamente definida pelo agente tem importância fundamental em relação aos demais, sem, entretanto, prescindilos.

Em termos relacionais, os indivíduos, agindo estrategicamente, são inseparáveis dos contextos transacionais em que estão implexos. Esses contextos estruturais (estados, governos, organizações, etc.), se isolados dos elementos que os integram, não deixam de ser meras abstrações vazias (EMIRBAYER, 1997, p. 287). O indivíduo, por sua vez, quando fora do contexto que justifica e fortalece suas ações, vê-se privado de forças que potencializam sua capacidade de agência, o que pode ser decisivo quanto à probabilidade de obter êxito em embates para consecução dos fins estrategicamente visados.

O potencial estratégico do agente, individual ou coletivo, é, portanto, diretamente dependente da sua capacidade de apreensão e de interpretação dos possíveis efeitos de variáveis contextuais e, a partir disso, de instrumentalizar suas ações em direção aos fins visados. Logo, em situações de mudanças intencionais da realidade, a capacidade de obtenção de conhecimentos durante a realização de ações faz com que não haja determinismos estratégicos e nem fórmulas prontas e acabadas aplicáveis independentemente de agentes sociais.

O interesse vinculado às estruturas é, portanto, delimitado pela capacidade de influência que elas podem exercer sobre as práticas sociais dos agentes, sem, contudo, aceitar que tal relação seja determinística ou que a estrutura se mantenha estável. As ações, por sua vez, por mais pessoais que sejam, não pertencem plenamente ao sujeito que as concebe e as executa, mas, em certa medida, ao sistema completo das relações nas quais e pelas quais se realizam (BOURDIEU et al., 1999, p. 32). Essas são, pois, as relações entre indivíduo e contexto da ação estratégica, que permitem a constituição de uma unidade de análise a partir de variáveis que emanam da coletividade imediata em que ele está implexo e que, em certo grau, pode influenciar e por elas ser influenciado. Compreender essas relações a partir da Teoria da Prática será essencial para que se potencialize a compreensão de arranjos de governança multinível em perspectivas capazes de expressar, além de suas estruturas facilmente identificáveis, as diferentes lógicas de formação e de articulação de poder, com base em diferentes capitais e práticas sociopolíticas.

\section{A Teoria da Prática em contexto de ação estratégica}

Nas seções que seguem, são discutidos os elementos essenciais delineadores e constitutivos da "Teoria da Prática", com foco em ações estratégicas executadas em contextos sociopolíticos.

\subsection{Premissas metodológicas e epistemológicas}

Com intenção de reverter a problemática construída pelo objetivismo, Bourdieu defende que uma teoria metodologicamente consistente para obtenção de conhecimento inerente a toda prática se impõe como condição prévia para o 
desenvolvimento de uma rigorosa ciência de práticas. Esforços teriam de ser voltados para construir um mundo social como sistema de relações objetivas, independentes da consciência e das intenções individuais (BOURDIEU, 1977).

Avançar na direção de uma teoria de práticas requer a identificação de princípios generativos situados no interior do movimento de geração delas próprias. Seria possível, assim, o desenvolvimento de uma ciência das relações dialéticas das estruturas objetivas por meio das quais a perspectiva objetivista do conhecimento daria acesso às disposições estruturadas dos agentes. A agregação de tais disposições levaria à atualização das estruturas objetivas que, por sua vez, influenciariam práticas futuras. Ciclo que tenderia a reproduzir-se dialeticamente (BOURDIEU, 1973). Portanto, o objetivo da análise da prática apreendida do mundo vivido não teria como propósito ampliar a subjetividade, mas explorar os limites da investigação objetiva (BOURDIEU, 1977, p. 7).

Antes de ser tratada a Teoria da Prática, em si, é importante situá-la em uma perspectiva epistemológica adequada. Para tal finalidade, o mundo social pode ser submetido a três modos, não mutuamente excludentes, de conhecimento teórico: fenomenológico, objetivista e praxeológico.

- Conhecimento fenomenológico: explicita verdades primárias do mundo social, considerando-as, como no mundo natural, autoevidentes por definição; logo, nega a possibilidade da autorreflexividade das ações práticas dos sujeitos. É, portanto, ponto de partida para o pensamento relacional, mas não teorizável por si mesmo.

- Conhecimento objetivista: constrói relações objetivas estruturando práticas e representações, assim, rompe com o conhecimento primário (prático e tácito), o que lhe confere características de autoevidência. Exemplo disso é o estruturalismo interpretativo, que se restringe à apreensão da verdade a partir da experiência primária e das estruturas objetivas do mundo social, sem considerar as condições específicas sob as quais elas se tornam possíveis no mundo da vida (BOURDIEU, 1973, p. 53). São abordagens originárias de análises substancialistas. Ingenuamente realistas, consideram cada prática em si e por si mesma, independentemente do universo de práticas intercambiáveis em que estão implexas. A correspondência entre as posições sociais e as práticas é tomada como mera relação mecânica e direta; logo, limitada por não abarcar a reestruturação dinâmica da capacidade de agência individual ou coletiva (BOURDIEU, 1996b, p. 16).

- Conhecimento praxeológico: por não se preocupar somente com o sistema de relações captadas objetivamente, pode contemplar também as relações dialéticas entre estruturas objetivas e as disposições estruturadas, produzidas e tendentes a serem reproduzidas. É gerado de um processo dual de internalização da exterioridade e de externalização da internalidade. Pressupõe uma ruptura com a produção objetivista de conhecimento, sem, contudo, desconsiderá-la. Há, na verdade, sua conservação e transcendência, na medida em que existe incorporação daquele conhecimento, que flui das práticas (BOURDIEU, 1977, p. $3)$. 
Embora Bourdieu considere o objetivismo metodológico como fase necessária em toda pesquisa, tenciona ir além com a construção da Teoria da Prática. Diferente da desvinculação do sistema de relações objetivas individuais ou coletivas historicamente construídas, como ocorre no objetivismo lógico. Com a Teoria da Prática, pretende viabilizar a construção de uma ciência experimental com fundamentos na dialética, transitando do opus operantum para o modus operandi, a exemplo da transição da ênfase na regularidade estatística ou da estrutura algébrica para os princípios subjacentes à produção dessa ordem observada.

Epistemologicamente, seria, portanto, viabilizada a identificação da lógica subjacente à geração das práticas e de suas representações mediante a captação empírica das estruturas de dado ambiente, por meio de regularidades associadas ao contexto socialmente estruturado: produto do habitus. É importante que isso seja coletivamente articulado para que não se constituam em produtos de ações orquestradas por um condutor (BOURDIEU, 1973, p. 63-64).

\subsection{Fundamentos teóricos do habitus}

Como elemento nuclear na Teoria da Prática, o habitus é entendido como um sistema de disposições duráveis e transponíveis que, integrando todas as experiências passadas, funciona como uma matriz de percepções, de avaliações e de ações. Ele torna possível a execução de uma variedade ilimitada de tarefas a partir de transferências analógicas de esquemas e de metáforas práticas, que permitem a resolução de problemas com constituições similares, mas com incessantes correções em função dos resultados obtidos previamente (BOURDIEU, 1973, p. 67).

Dialeticamente produzido, o habitus permite a produção e a reprodução de práticas ajustadas a diferentes condicionantes contextuais situados de maneira espaçotemporal. Nessa perspectiva, as práticas tendem a produzir regularidades objetivas que, por sua vez, permitem a explicitação de seus princípios generativos enquanto se ajustam às demandas inseridas como potencialidades objetivas em situação enfrentada diretamente pelo agente, individual ou coletivamente (BOURDIEU, 1973, p. 67).

O habitus, como parâmetro de constante geração de improvisações reguladas, produz práticas propensas a reproduzirem as regularidades de condições objetivas sustentadas por seu princípio de geração, enquanto é influenciado e tende a se ajustar às demandas inseridas como potencialidades objetivas na situação diretamente confrontada. Assim, as práticas não podem ser diretamente deduzidas de um conjunto fixo de condições objetivas ou condições que produziram o habitus, mas da interação entre ações estratégicas do agente em relação a condicionantes do habitus incidentes especificamente sobre a prática levada a efeito. O habitus funciona como um operador que, de fato, permite o relacionamento entre os sistemas de relações objetivas e subjetivas pela produção da prática (BOURDIEU, 1973, p. 67). 
A teorização de Bourdieu em torno do habitus permite explicações sobre os motivos pelos quais a prática se diferencia da interação social, da consciência prática, da racionalidade discursiva ou da institucionalização de regras. No contexto de estudos sobre práticas estratégicas, o habitus se sobressai como elemento importante por explorar a defasagem de estruturas sociais interiorizadas pela história no âmbito das formações sociais e a necessária improvisação social dos agentes para se posicionarem e influenciarem a realidade. A prática, portanto, deixa de ser a simples repetição mecânica de estratégias adotadas no passado. Condicionantes do passado têm sua importância, mas os efeitos das estratégias são dinamicamente definidos pelo conhecimento adquirido pelo agente durante a execução da sua própria intencionalidade em relação aos fins visados.

\subsection{Relaçôes entre práticas e habitus no contexto da ação estratégica}

No contexto da teoria da ação, diferentes de simples sujeitos, há a figura dos agentes. São agentes porque detêm algum domínio sobre princípios geradores e organizadores de suas práticas e representações, ações e pensamentos. Os indivíduos são agentes na medida em que atuam intencionalmente e possuem conhecimentos sobre a realidade, são dotados de um senso prático e detentores de um sistema adquirido de preferências, de classificações e de percepções (BOURDIEU, 1996b, p. 44). Por serem agentes, potencializados em função das diferentes capacidades individuais e coletivas, é que podem se posicionar estrategicamente para criação de oportunidades por meio de diferenciação de posturas políticas para configuração dinâmica do escopo de objetivos.

Pautados em conhecimentos historicamente adquiridos, os agentes obtêm vantagens uns sobre os outros em decorrência do menor ou maior nível de necessidade de obediência a regras externas, ou de se submeterem, mesmo que implicitamente, a constrangimentos institucionais determinantes. O agente, portanto, deixa de ser visto como mero produto estrutural da história construída com base em relações de poder. Ele, no exercício do improviso social utilizado para concepção e execução de suas estratégias, não pode ser visto como simples meio de adequação a fins prévia e conscientemente formulados. A necessidade de improvisação para agir estrategicamente supõe que as ações subjetivas conscientes são, em grande parte, resultados posteriores à prática, não sua origem ou explicitação.

Infraconsciente e parcialmente autônomo, o habitus se constitui em uma espécie de segunda natureza, que, situado historicamente, vincula o agente a dado meio social, permitindo-lhe o desencadeamento de ações sem cálculos ou controles conscientes, dispensando, desse modo, a predefinição dos fins. O habitus contém em si o conhecimento e o reconhecimento das regras do jogo, cuja aquisição ocorre mediante aprendizagem explícita ou implícita. Opera como um sistema de esquemas geradores de estratégias, que podem ser objetivamente conformadas aos interesses dos seus autores, sem, entretanto, terem sido concebidas com tal fim (THIRY-CHERQUES, 2006, p. 34). 
Como princípio de geração de estratégias para enfrentar imprevistos e mudanças rumo ao futuro, as práticas produzidas pelo habitus, mesmo vinculadas a propósitos futuros explicitamente declarados, são determinadas pela antecipação implícita das suas consequências. As práticas tendem, portanto, a reproduzir as estruturas objetivas das quais são produtos (BOURDIEU, 1973, p. 65; 1985, p. 205-210), enquanto as estratégias, com base naquilo que é estruturado pelas práticas concretizadas, voltam-se para tentar mudar realidades futuras.

Assim, o habitus, em si, gera uma sequência de movimentos que são objetivamente organizados como estratégias, sem, entretanto, serem produtos de uma intenção verdadeira ou de domínio completo do agente, por exemplo, posicionada como uma dentre várias estratégias possíveis. Logo, estímulos convencionais e condicionais atuando como elementos simbólicos, perceptíveis por aqueles que estão capacitados para fazê-lo, tendem a ser impostos e, necessária e incondicionalmente, aceitos quando rompem com a consciência, já que se constituem em caminhos cujos traços foram definidos a priori (BOURDIEU, 1973, p. $65 ; 1985$, p. 205-210). É a ação premeditada escapando da capacidade cognitiva, do tempo mínimo ou dos demais recursos necessários para reação pelos demais agentes envolvidos na ação, que permite o resultado diferencial decorrente da execução prática da estratégia.

Por outro lado, os agentes não se constituem em meras "partículas" que são mecanicamente puxadas ou empurradas por forças externas (BOURDIEU; WACQUANT, 1992, p. 108). Permanecerá sempre a possibilidade de as respostas do habitus serem acompanhadas de cálculos estratégicos tendentes a executar, quase conscientemente, o que o habitus executa mediante estimativa das possibilidades de transformação do efeito passado no efeito futuro esperado. Tais respostas estão primariamente relacionadas às potencialidades objetivas do campo quanto às possibilidades de ação ou não ação dos agentes no presente, como oposição a possibilidades absolutas futuras que excluem deliberações (BOURDIEU, 1973, p. 64).

Em termos práticos, sob influência do habitus, a avaliação subjetiva quanto às possibilidades de êxito decorrentes do desencadeamento de uma ação específica traz à tona princípios inconscientes do ethos. É uma disposição geral, que, por ser fruto de aprendizagem dominada por regularidades objetivas, sugere comportamentos considerados arrazoados ou desarrazoados dos agentes sujeitos a tais regularidades. Desse modo, surgem disposições duráveis em relação às quais as práticas podem ser adaptadas ou ajustadas previamente às possibilidades objetivas incorporadas. Com isso, os agentes, mais ou menos conscientes, tendem a considerar desnecessários os cálculos mais simples para estimar possibilidades de êxito, ou para decidir pelo descarte de alternativas sem mesmo examiná-las. É como se a experiência passada incorporada no habitus determinasse subjetiva e aprioristicamente probabilidades quanto a eventos futuros pela geração de percepção que permite avaliação em relação a toda nova experiência que se apresente como possibilidade (BOURDIEU, 1969, p. 17-18; 1973, p. 65).

Em uma perspectiva temporal, o conceito de habitus se apresenta como elemento integrador que explica a incidência de uma força social sobre as práticas, 
mas não, necessariamente, de maneira linear ou fluida. A histerese, nesse processo, corresponde aos efeitos retardados pela mediação entre a incorporação no habitus e a consequente sedimentação sequencial de novas capacidades e de disposições temporais nos agentes em dado campo (WACQUANT, 2006, p. 17). Os efeitos da histerese implicam necessariamente na lógica da gênese de habitus e em seus reflexos sobre as disposições dos agentes. Evidência disso é o fato de as práticas sempre serem expostas a sanções negativas quando o ambiente a que deverão confrontar se diferenciar consideravelmente daquele em relação ao qual foram e estão objetivamente ajustadas. Em outras palavras, as práticas são consonantes com o habitus que as gerou, mas não em função das recentes transformações e ajustes sofridos por tal habitus. Abrem-se, assim, espaços para conflitos entre disposições influenciadas pelo habitus produzido em função do que diferentes gerações de agentes consideram que é impossível, possível, provável e seguro. Nessa situação, um grupo experiente concebe como naturais e razoáveis as mesmas práticas que outro julga inimagináveis, absurdas e vice-versa (BOURDIEU, 1973, p. 65).

Diante dessa lógica, são insustentáveis teorias que, explicita ou implicitamente, tratam a prática como uma reação mecânica, determinada diretamente por condições antecedentes e inteiramente redutíveis ao funcionamento de mecanismos preestabelecidos, como modelos, normas ou papéis (BOURDIEU, 1973, p. 65). Se assim fosse, teria de ser aceita a suposição de que tais mecanismos existem em número infinito e como se fossem configurações fortuitas de estímulos capazes de dispará-las exteriormente. Entretanto, a rejeição dessa perspectiva mecanicista não implica atribuir poder de livre determinação criativa para produzir e atribuir significados a dada situação a partir da projeção de objetivos e, em função disso, indicar sua transformação. Do mesmo modo, em relação às intenções conscientes e deliberadas dos seus autores, não é permitida a redução das intenções objetivas e significações como consequentes de ações. A prática é, pois, necessária e relativamente autônoma em relação à situação imediatamente considerada por ser resultante da relação dialética entre uma situação, uma intencionalidade estratégica e um habitus (BOURDIEU, 1973, p. 65).

Dessa forma, não é possível admitir a existência de regras fixas e pontuais para previsão antecipada e precisa de resultados decorrentes de práticas influenciadas pelo habitus. Considerar, pois, dinamicamente o desenvolvimento da ação no tempo é imprescindível. A incerteza existirá, mesmo nos casos em que o habitus e as disposições dos agentes estejam em perfeita harmonia e em que as ações e reações sejam perfeitamente entrelaçadas e exteriormente predizíveis. Nessas condições, quanto ao resultado da interação, a incerteza permanecerá enquanto a sequência de ações e reações não for concluída. Essa incerteza é suficiente para mudar não apenas a experiência da prática, mas também a própria prática. Estrategicamente, há, portanto, a abertura de possibilidades para, dinamicamente, adotar-se ações para evitar o resultado mais provável. Desse modo, abolir o tempo como elemento integrante da análise é também abolir a possibilidade de ação estratégica por meio das ou sobre as práticas (BOURDIEU, 1977, p. 6; 9). 
O habitus se constitui em categoria mediadora no espaço social, transcendendo a fronteira entre o objetivo e o subjetivo (WACQUANT, 2006, p. 17). O habitus é tanto um sistema de esquemas da produção de práticas quanto

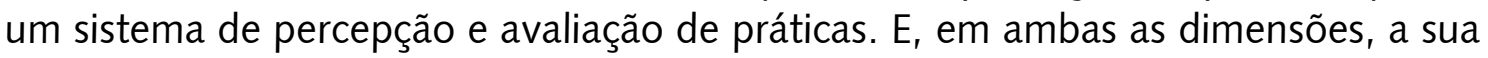
operação expressa a posição social na qual foi elaborado (BOURDIEU, 1989b, p. 19). O habitus, como produto da história, produz práticas individuais e coletivas em conformidade com os esquemas generativos prévios. É como um passado que sobreviveu no presente e que tende a perpetuar-se no futuro, gerando continuamente práticas estruturadas conforme os seus princípios (BOURDIEU, 1973, p. 73).

Como as condições de existência tendem, pelo menos parcialmente, a produzir sistemas de disposições semelhantes, a relativa homogeneidade do habitus resultante após cada prática propicia uma harmonização objetiva de práticas que the conferem regularidade e objetividade e, em consequência, definem sua racionalidade específica. Daí surge a possibilidade de sustentação de ações dadas como evidentes ou com alta probabilidade de estarem certas - ou como imediatamente inteligíveis e predizíveis - por todos os agentes que detêm domínio prático do sistema de esquemas de ação e interpretação objetivamente implicados em dada situação de sua execução (BOURDIEU, 1973, p. 68).

De modo geral, a avaliação quanto à previsão da aceitação de práticas é diretamente dependente do maior ou menor domínio do habitus detido pelos agentes nelas envolvidos. Se os agentes são mais dominados pelo habitus do que o dominam, é porque o habitus atua como princípio de organização de suas ações; logo, esse meio informa todo o pensamento, toda a ação e, inclusive, o pensamento da ação. O nível de influência a que se sujeita o agente revela-se pelo grau de congruência entre suas práticas e o habitus do qual resultaram (BOURDIEU, 1977, p. 18). Em perspectivas avaliativas das influências do habitus em ações estratégicas, da sua percepção instrumentalizada pelo conhecimento dos agentes envolvidos é que resultará o grau que influenciará o nível de impacto nos resultados estratégicos pretendidos.

A concordância coletiva com práticas entre agentes tende a torná-los membros de grupos ou classes por considerarem condições objetivas idênticas. Há, assim, um efeito universalizante e particularizante na medida em que tal racionalidade homogeneíza membros do grupo por distinção frente a outros grupos (BOURDIEU, 1973, p. 68). No âmbito de cada coletividade, as ações, ao sofrerem influências do habitus construído historicamente, tendem a ser conformadas por certo mimetismo expresso por práticas vigentes em períodos e contextos específicos (BOURDIEU; WACQUANT, 1992, p. 124). Desse modo, por meio do habitus são apreendidos os princípios de condução que conferem regularidade, unidade e sistematicidade às práticas de um grupo ou classe (BOURDIEU, 1973, p. 68-69).

As práticas dos membros de um mesmo grupo em uma sociedade diversificada, como resultantes de disposições internalizadas como estruturas 
similares, são objetivamente concertadas e possuem significados unitários e sistemáticos; logo, transcendem intenções subjetivas e conscientes de projetos individuais (BOURDIEU, 1973, p. 71). As estratégias individuais são, portanto, decisivas para a inserção do agente em grupos, bem como os valores internalizados pelos grupos são condicionamentos fortes a serem enfrentados pelo estrategista que procura agir com legitimidade, com base nas forças e condicionantes do grupo.

A harmonização objetiva de um grupo em função do habitus resulta no fato de as práticas, mesmo na ausência de qualquer concertação explícita, colocarem-se objetivamente em situação de harmonia sem qualquer interação direta. Sendo assim, as práticas dos membros do mesmo grupo de agentes tendem a ser sempre mais e melhor afinadas do que as dos agentes, individualmente considerados, porque a harmonia coletiva decorre do respeito às próprias leis que as formam e as integram como possíveis e viáveis. O habitus seria justamente essa lei imanente incorporada em cada agente como sua educação básica em relação à lógica de funcionamento do grupo. Assim, o habitus não é só uma condição de concertação de práticas, mas também uma prática de concertação. $O$ resultado disso é que correções ou ajustes conscientemente executados pelos agentes pressupõem o domínio de um código comum. Portanto, as tentativas de mobilização coletiva têm seu sucesso condicionado pela existência de um mínimo de concordância entre o habitus dos agentes de mobilização e as disposições daqueles cujas aspirações pretendem expressar (BOURDIEU, 1973, p. 69-70).

Cada agente é produtor e reprodutor da significação objetiva coletivamente formada. Assim o é por suas ações serem o produto de um modus operandi do qual o agente não é o produtor e do qual não possui o domínio plenamente consciente, uma vez que elas contêm uma intenção objetiva, que sempre excede as intenções conscientes do próprio agente (BOURDIEU, 1973, p. 70). Em decorrência das disposições adquiridas, representadas pela intensidade de domínio habitus, os agentes definem "maneiras permanentes de ser, que podem, em particular, levá-los a resistir, a opor-se às forças do campo" (BOURDIEU, 2004, p. 28).

\subsection{Dinamicidade histórica do habitus}

As ações coletivas são, portanto, resultantes de uma conjuntura. De uma conjunção necessária de disposições e um evento objetivo. Logo, a conjuntura, como transformadora de práticas objetivamente coordenadas em função de necessidades objetivas similares na ação coletiva, é o resultado da relação dialética entre as disposições dos agentes e o evento. Sem serem totalmente coordenadas, vez que resultantes da série causal caracterizada por diferente duração estrutural, as disposições e a situação, combinadas sincronicamente para constituir uma conjuntura determinante, nunca são totalmente independentes, haja vista que são engendradas por estruturas objetivas. Assim, a histerese do habitus, que apresenta implicações na lógica do processo de reprodução das estruturas constituintes do próprio habitus, se apresenta como fundamento para a existência de lacuna estrutural que leva à perda de oportunidades estratégicas, especialmente à 
incapacidade para analisar crises históricas de acordo com as categorias de percepção passadas (BOURDIEU, 1973, p. 74).

\section{Espaços e campos sociais de interações estratégicas}

O mundo social é constituído a partir de uma gênese em que, de um lado, há os esquemas de percepção, pensamento e ação constitutivos do habitus, e, de outro, existem as estruturas sociais representadas pelos campos inseridos em espaços ou estruturas sociais mais amplas (BOURDIEU, 1989b, p. 14).

$\mathrm{Na}$ Teoria da Prática, com fundamentos no habitus, a apreensão e a representação da complexidade de relações sociais é possível a partir de esquemas de percepção, pensamentos e ação, enquanto a sua contextualização ocorre em espaços ou estruturas sociais mais amplas, chamadas campos. Nos campos, ajustes de habitus poderão ocorrer em perspectivas longitudinais historicamente consideradas; e em perspectivas transversais, normalmente pelo confronto entre habitus constituídos em categorias sociais especializadas e institucionalizadas.

Em um processo dual de internalização e externalização, no ritmo em que novas ações são desencadeadas, as práticas são historicamente incorporadas nos habitus que, em certa medida, tenderão a concertar futuras ações no campo (BOURDIEU, 1973, p. 67). Como consequência, futuras inserções de agentes no campo implicam na sua inserção na própria história do campo, por meio do conhecimento e do reconhecimento da problemática desenvolvida e praticamente instituída e articulada (BOURDIEU, 1989a, p. 59). O habitus, portanto, não é determinista, mas, até certo ponto, influenciável e influenciador de práticas em dado campo social e politicamente situado.

\subsection{Fundamentos teórico-conceituais dos campos como espaços, práticas e estratégias}

O espaço social é constituído por diferenciações, o que permite divisões. É o espaço em que grupos e classes existem, de algum modo, em estado virtual. Não como um dado, mas como algo em permanente processo de construção. É algo que os agentes sociais, em ambiente permeado por relações de cooperação e conflito, têm a fazer, a construir, individual e, sobretudo, coletivamente; logo, essa construção não ocorre em um vácuo social. A definição do espaço social é, pois, constantemente sujeita a ações de agentes a partir de sua posição definida pela posse de diferentes tipos de capital e sujeita a condicionantes estruturais (BOURDIEU, 1989b, p. 18; 1996b, p. 26-27).

Para apreender e explicitar esse espaço, não se pode capturar a lógica mais profunda da realidade social sem a submersão ao nível das particularidades do contexto empírico, historicamente situado. Tal lógica só é passível de ser construída como caso particular do possível, mediante análises comparativas de espaços sociais, cujo objetivo é apanhar o invariante, a estrutura, na variante observada (BOURDIEU, 1996b, p. 14-15).

Dentre as invariantes, destacam-se a distribuição do poder e seus monopólios, as suas lutas e estratégias para obtenção de vantagens e a defesa de 
interesses (BOURDIEU, 1975, p. 19). Essas invariantes, no funcionamento do campo, constituem o nomos (THIRY-CHERQUES, 2006, p. 38), que é resultado de um processo de socialização por meio do qual há inculcação nos agentes de uma visão ou divisão do mundo. É um princípio de construção e um dos elementos constituintes do habitus. É tanto individual quanto coletivo. É uma lei tácita de percepção e prática que está na base do consenso, no sentido do mundo social, na base do sentido comum (BOURDIEU, 1996a, p. 21).

Logo, ao analista que pretenda apreender objetivamente os princípios de construção do espaço social ou os mecanismos de reprodução desse espaço, em relação aos quais crê poder representar um modelo com pretensões de validade universal, pode indicar as diferenças reais que separam tanto as estruturas quanto as disposições. Isso deve ocorrer não pela singularidade das naturezas, mas nas particularidades de diferentes histórias coletivas (BOURDIEU, 1996b, p. 14-15). Empreendimentos como esses requerem percepção acurada do que é o espaço social, definido como espaço multidimensional, relativamente autônomo, sustentado por princípios de diferenciação ou de distribuição formados por um conjunto de propriedades ativas, capazes de conferir força e poder dentro de tal universo aos agentes que o constituem e, nele, lutam por posições (BOURDIEU, 1985, p. 196).

\subsection{Origens e implicaçôes do conceito de campo}

O campo social, ou espaços de relações objetivas detentores de lógica própria, não é reproduzido e não é redutível em função da lógica que rege outros campos. É tanto um "campo de forças" - uma estrutura que constrange os agentes nele implexos - quanto um "campo de lutas" - em que os agentes atuam conforme suas posições relativas, conservando ou transformando sua estrutura (BOURDIEU, 1996b, p. 50).

Estabelecendo analogia com conceitos da Física, Bourdieu explicita os fundamentos do conceito de campo nos seguintes termos:

Um campo, que não pode ser reduzido a um simples agregado de agentes isolados ou à soma de elementos meramente justapostos, é como um campo magnético composto por linhas de força" (BOURDIEU, 1969, p. 89).

Quando falo campo, sei muito bem que neste campo encontrarei "partículas" (deixe-me imaginar por um momento que estamos tratando com um campo físico) que estão sob influências de forças de atração, de repulsão, e assim por diante, como em um campo magnético. Tendo dito isto, assim que eu fale de um campo, a minha atenção fixa-se na primazia deste sistema de relações objetivas sobre as próprias partículas. E podemos dizer, seguindo a fórmula de um famoso físico alemão, que o indivíduo, como o elétron, é um Ausgeburt des Felds [Produto do Campo]: ele ou ela são de certo modo uma emanação do campo (BOURDIEU; WACQUANT, 1992, p. 106-107). 
Os campos são, assim, constituídos por agentes ou sistemas de agentes e podem ser representados a partir das muitas forças, de repulsão ou atração, que tornam possível sua existência e determinam sua estrutura específica em dado momento no tempo (BOURDIEU, 1969, p. 89). O campo, se comparado com um jogo, se diferencia por nele as próprias regras estarem postas em jogo (BOURDIEU, 2004, p. 29). Dada a instabilidade natural dos campos, a sua instituição, manutenção e possibilidade de perpetuação são dependentes da capacidade estratégica de concretização de ações que o fortaleçam como unidade de agregação potencializadora da capacidade de agência individual. Nesse ponto, há importantes aspectos a serem considerados e explorados para formação de realidades manifestas com alguma profundidade a partir do conceito de governança nas suas diferentes aplicações (por exemplo, governança territorial, urbana, pública, corporativa, etc.).

O conceito de campo é passível de ser aplicado em diferentes escalas, desde as mais amplas até as mais circunscritas. Cada configuração passa a delimitar um microcosmo com sua própria lógica de poder (EMIRBAYER; WILLIAMS, 2005, p. 692). Implexos nesses espaços de jogos, os agentes e grupos de agentes são definidos pelas suas posições relativas ocupadas. A cada um deles é atribuída uma posição ou uma classe precisa de posições adjacentes, de modo que cada um não pode ocupar concomitantemente duas regiões opostas em tal espaço. Essa impossibilidade é justificada pelas propriedades selecionadas para construir esse espaço por as forças serem ativas, e, assim, cada uma pode ser vista como um campo de forças em si (BOURDIEU, 1985, p. 196). O espaço social apresenta-se na forma de agentes dotados de diferentes propriedades que são sistemática e objetivamente relacionadas entre si (BOURDIEU, 1989b, p. 19; 2004, p. 23).

\subsection{Implicações do conceito de capital como recurso estratégico para formação de campos}

A estrutura de um campo particular, em qualquer momento, é definida pelo estado da distribuição de poder entre os agentes ou instituições protagonistas, ou seja, pela estrutura da distribuição do capital específico. O capital, per se, não existe, senão como elemento simbólico que funciona para analisar a atribuição de poder em dado campo (BOURDIEU; WACQUANT, 1992, p. 101). A distribuição do capital resulta de relações prévias objetivadas em instituiçõos e disposições, influenciando as estratégias e as possibilidades objetivas dos diferentes agentes ou instituições nas relações presentes (BOURDIEU, 1975, p. 27).

Em relação dialética, a estrutura da distribuição de capital é a fonte de transformações do campo por meio de estratégias de conservação ou de subversão da estrutura que a própria estrutura produz. De um lado, a posição que cada agente individual ocupa na estrutura do campo em qualquer momento é a resultante - "cristalizada" em instituições e disposições - da soma das estratégias prévias de tal agente e de seus concorrentes. De outro lado, as transformações da estrutura do campo são produtos de estratégias de conservação ou subversão cuja orientação e eficácia são provenientes das propriedades das posições nele ocupadas por aqueles que o produzem (BOURDIEU, 1975, p. 27). 
Os campos não são estruturas fixas. São resultantes da história da dinâmica das suas posições constitutivas e das disposições prevalecentes dos agentes neles implexos (BOURDIEU, 2001, p. 129). Na construção do campo, as propriedades ativas selecionadas como princípios da construção do espaço social se constituem em distintas naturezas de poder ou capital, atualizadas em outros diferentes campos. Desse modo, por um lado, emergem as bases de um conjunto de relações objetivas de poder que se impõem a todos os agentes que se relacionam no campo, e que são irredutíveis às suas intenções individuais ou às interações diretas entre eles (BOURDIEU, 1985, p. 196). Por outro, o campo, em função de sua relativa autonomia, tem capacidade de refratar pressões ou demandas externas por meio de retraduções, de modo que a autonomia de um campo tem por indicador seu poder de refração e de retradução (BOURDIEU, 2004, p. 22).

Os campos, portanto, não são estruturas objetivas independentes das características dos seus ocupantes e nem inertes às influências de outros campos a eles contínua ou ocasionalmente conexos. São microcosmos sociais constituídos a partir da articulação de diferentes capitais e interesses específicos (THIRYCHERQUES, 2006, p. 36). O capital objetivado, material ou simbolicamente, e acumulado durante o tempo, representa poder em dado momento no campo. Dentre outras possibilidades, o capital pode se configurar em capital econômico, capital cultural, capital social, capital simbólico (BOURDIEU, 1985, p. 196-197; 1989b, p. 17). A magnitude de cada tipo de capital pode variar, em cada campo, entre dois limites teóricos, que, de fato, nunca são atingidos: em um extremo, a situação de um monopólio do capital específico por dado agente; noutro, a situação da concorrência perfeita decorrente da igual distribuição de tal capital entre todos os competidores (BOURDIEU, 1975, p. 29).

Por essas razões, a posição de dado agente implexo em um espaço social pode ser definida por meio das posições por ele ocupadas nos diferentes campos em função da distribuição de poderes emanados de capitais diversos, percebidos e reconhecidos como legítimos quando ativados no interior de cada campo. Assim, cada espécie de capital pode instituir um modelo simplificado de campo social que, como um todo, permite definir, para cada agente, a sua posição nos possíveis espaços de competição. Cada um desses espaços de competição tem lógicas e hierarquias próprias. A hierarquia que prevalece entre diferentes tipos de capital e a conexão entre os diferentes tipos de recursos tende a impor a sua própria lógica a outros campos (BOURDIEU, 1985, p. 197).

Considerando a relação com os agentes neles implexos ou com eles envolvidos, os campos sempre incluem certa medida da arbitrariedade social, já que são influenciados para servirem a interesses de agentes posicionados dentro e fora deles. Entretanto, isso não frustra a lógica inerente aos campos e, especialmente, a luta entre os agentes dominantes e os novos entrantes, com o transversal controle resultante de causar, em certas condições, desvios sistemáticos de fins para alcançar interesses individuais, o que continuamente funciona como elemento de dinamização em proveito da evolução do próprio campo (BOURDIEU, 1975, p. 32). 
Como microcosmos com certa autonomia no interior do mundo social, os campos se interpenetram e se relacionam (THIRY-CHERQUES, 2006, p. 41). Mais precisamente, o campo social pode ser expresso como um espaço multidimensional de posições em que toda posição real pode ser definida em termos de um sistema multidimensional de coordenadas cujos valores correspondem aos valores das diferentes variáveis pertinentes. Nesse sistema, de acordo com o peso relativo dos diferentes tipos de capitais possuídos em relação aos recursos totais, os agentes são distribuídos. Na primeira dimensão, de acordo com o volume total de capital sob seu domínio e, na segunda, em função da composição de seu capital (BOURDIEU, 1985, p. 197; 1989b, p. 17). Em termos práticos, um exemplo de configuração objetiva da estrutura de um campo pode ser obtido a partir da análise de grafos, que espelham estruturalmente as redes sociais, e pela lógica discursiva que manifesta as particularidades do arranjo de governança estruturado pela rede (vide, por exemplo, PROCOPIUCK; FREY, 2009a; 2009b; ROSA et al., 2009).

\section{Relações e definição de posições dos agentes em campos sociais}

O entendimento da complexidade das relações nos campos sociais requer o conhecimento adequado do espaço de relações objetivas entre as diferentes posições que os constituem e das necessárias relações instituídas - ainda que haja a mediação do habitus dos seus ocupantes - entre essas posições e as posturas a elas correspondentes. A delimitação objetiva de classes construídas, ou de regiões do espaço construído de posições, permite entender o princípio e a eficácia das estratégias classificatórias por meio das quais os agentes procuram conservar ou modificar tal espaço, diante do que ocorre a constituição de grupos organizados com a intenção de defender interesses dos seus membros (BOURDIEU, 1985, p. 209).

Em uma perspectiva de posicionamento estratégico, a dinâmica do campo reside na sua forma e na sua estrutura, em particular, nas distâncias, lacunas e assimetrias entre várias forças que se confrontam no seu interior. Essas forças são representadas pela posse e articulação de diferentes tipos de capitais pelos agentes (BOURDIEU; WACQUANT, 1992, p. 101). Nesse ponto, a policy network analysis apresenta potenciais significativos para contribuir e receber contribuições de estudos pautados na lógica dos campos e de seus elementos constituintes (PROCOPIUCK, 2013).

\subsection{Articulação estratégica entre agentes e configuração de campos}

A forma assumida pelos campos em dado momento de um processo de transformação constante é função da distribuição conjunta de diferentes espécies de capital. O capital define o estado das relações de poder sustentadas por status sociais institucionalizados, socialmente reconhecidos ou legalmente garantidos, em um processo de longa duração entre agentes sociais objetivamente definidos pela sua posição nessas relações. Sob tal lógica, há a determinação de poderes potenciais ou reais no interior de diferentes campos e as possibilidades de acesso 
aos benefícios específicos por eles viabilizados. Assim, o conhecimento da situação dos agentes em tal espaço é fonte de informações quanto às suas propriedades posicionais intrínsecas e suas propriedades relacionais (BOURDIEU, 1985, p. 197). Propriedades passíveis de serem, em parte, capturadas e objetivamente mensuradas por meio da social network analysis (GALASKIEWICZ; WASSERMAN, 1993; WALKER; WASSERMAN; WELLMAN, 1993; GALASKIEWICZ; WASSERMAN, 1994; WASSERMAN; FAUST, 1997).

As consequências práticas provenientes do conhecimento auferido a partir das propriedades posicionais e relacionais dos agentes em dado campo social são representadas por possibilidades de efetuar agrupamentos de agentes que ocupam posições semelhantes, e quando submetidos a condições equivalentes, que tendem a reagir com alguma uniformidade quanto a disposições ou interesses, ou à adoção de práticas ou posturas correlatas (BOURDIEU, 1989b, p. 17; 2001, p. 189).

Sem serem mecânicas ou determinísticas, as disposições adquiridas por meio da interiorização de estruturas sociais são flexíveis e possuem diferentes intensidades quanto à força. Refletem o exercício da faculdade de ser condicionável, com capacidade natural de adquirir capacidades não naturais, arbitrárias. Como rotinas corporais e mentais resultantes de aprendizagem tácita, expressam uma atitude "natural" que viabiliza a ação não premeditada em consonância com as regras subjacentes que estruturam determinado meio (BOURDIEU, 2001, p. 189).

Embora os campos não se constituam em grupos reais, pois mais se aproximam de grupos possíveis, abrem espaços para explicação e predição de práticas e propriedades. Dentre tais possibilidades - levando em conta compatibilidades e incompatibilidades, proximidades ou distâncias entre agentes -, se destaca a explicitação dos motivos vinculados à propensão de certos agentes para formação de grupos, manutenção de um senso de grupo, e daqueles relacionados às capacidades estratégicas de mobilização (BOURDIEU, 1985, p. 198). De tal configuração, as redes sociopolíticas estruturadas em multiníveis em função de cada momento da formação e de execução de políticas públicas são exemplos (PROCOPIUCK, 2013).

A definição de grupos de agentes a partir de suas práticas e articulações cotidianas de diferentes capitais para mudar suas posições permite uma representação integrada e objetiva de dado mundo social. E, concomitantemente, explicar mais precisamente como coletivamente os agentes levam em consideração as contribuições individuais em direção à construção de uma visão do mundo social e, por meio disso, à concretização da construção de tal mundo. Assim, por meio do trabalho da representação, continuamente executado por cada agente para impor uma visão do mundo ou a visão da sua própria posição nesse mundo, há a definição de sua identidade social (BOURDIEU, 1985, p. 200).

A percepção do mundo social é, assim, produto de uma dupla estruturação social: objetiva e subjetiva. A esfera objetiva é socialmente estruturada em razão das propriedades atribuídas a agentes ou instituições não surgirem independentemente da percepção da sua posse de dados tipos de capitais, mas em combinações com probabilidades desiguais. A esfera subjetiva, por sua vez, é 
estruturada em decorrência dos esquemas de percepção e avaliação disponíveis e utilizados em dado momento por cada indivíduo. Nesse ponto, especial atenção merecem aqueles consubstanciados na linguagem, por serem produtos de lutas simbólicas prévias e, assim, expressarem o estado das relações simbólicas de poder depositadas nos princípios de visão de mundo, de modo relativamente transfigurado (BOURDIEU, 1989b, p. 20; 1989a, p. 102).

\subsection{Visão de mundo e posicionamento estratégico dos agentes no campo}

No contexto social, por um lado, a incerteza se constitui no elemento que sustenta a pluralidade de visões de mundo. Por outro, as lutas simbólicas por poder procuram produzir e impor uma legítima visão de mundo. São estratégias cognitivas implícitas ou explícitas para produção de significação a objetos do mundo social para além de atributos diretamente identificáveis por meio de referência ao futuro ou ao passado (BOURDIEU, 1985, p. 201).

A percepção do mundo social tem seus fundamentos na construção de um sentido de lugar em função das posições ocupadas no espaço social por meio de um domínio prático da estrutura social que, no conjunto, se revela pelo sentido das posições nela ocupadas pelos diferentes agentes (BOURDIEU, 1985, p. 201). $\mathrm{Na}$ busca de posicionamento em diferentes campos, o agente é capaz de, ativamente, apreender a realidade, formar e tentar impor sua visão do mundo, mas a construção é executada sob constrangimentos estruturais que podem facilitar ou dificultar sua inserção e seu posicionamento (BOURDIEU, 1989b, p. 18; 20).

No posicionamento dos agentes em dado campo, tem destaque o capital simbólico apropriado. Em essência, os sistemas simbólicos são construídos sob a lógica da diferença, cujos elementos inclinam os agentes a aceitar o mundo social como ele é, tomá-lo por certo, ao invés de rebelarem-se e contraporem-se a ele. O sentido de lugar, como sentido do que cada um pode ou não pode permitir-se, implica na aceitação tácita da posição de cada um. Há, com isso, emergência de um sentido de limites, de importância, de distanciamento, para ser marcado e mantido, respeitado ou esperado nas interações entre agentes. O sentido de lugar se apresenta com maior intensidade onde as condições de existência são mais rigorosas e onde o princípio de realidade mais rigorosamente se afirma (BOURDIEU, 1985, p. 203-205). "A dominação não é efeito direto da luta aberta, do tipo 'classe dominante' versus 'classe dominada', mas resultado de um conjunto complexo de ações infraconscientes, de cada um dos agentes e cada uma das instituições dominantes sobre todos os demais" (BOURDIEU, 1996b, p. 50).

Quanto a esses aspectos, a policy network analysis pode ser promissora para aproximar a concepção de espaços sociais como espaços de ações políticas voltadas para busca de resultados teórica e empiricamente manejáveis, com vistas a explicitar variáveis e explicar como a ação política se desenvolve sob a lógica relacional de redes de políticas. 


\subsection{Arbitrariedade simbólica e limitação da ação estratégica no campo}

As categorias da percepção do mundo social, quanto às suas características mais essenciais, são produtos da internalização e incorporação das estruturas objetivas do espaço social, e se constituem em verdadeiro capital simbólico distribuído entre agentes que se articulam estrategicamente em tal espaço (BOURDIEU, 1999, p. 336). A noção de capital simbólico (comumente nominado prestígio, reputação, etc.), representando relações de força exercidas por relações de cognição e de comunicação, se constitui a partir da síntese de três tradições teóricas: do construtivismo emprega a noção de que os esquemas simbólicos se constituem em instrumentos de construção do mundo de objetos; da tradição interpretativa ou estruturalista que, em especial em Habermas, o trata como instrumento de comunicação, reduzindo questões de poder e de política a questões de significação; finalmente, das tradições que veem nos símbolos instrumentos de poder ou de legitimação de poder, como em Marx, priorizando o aspecto econômico, ou em Nietzsche, o político (BOURDIEU, 1999, p. 336).

No capital simbólico se assenta a autoridade que atribui eficácia formativa ao discurso sobre o mundo social, à força simbólica que define visões e prediz apontando para princípios imponentes de visão e de divisão do mundo social (BOURDIEU, 1985, p. 203-205). A consequência prática disso é que se constituem em elementos de um sistema simbólico como instrumento de construção da realidade, definido a partir da função dos símbolos, sem considerar as funções sociais (BOURDIEU, 1979, p. 77). Esses sistemas simbólicos são instrumentos de conhecimento que exercem poder estruturante na medida em que são estruturados e, assim, tendem a estabelecer uma ordem gnoseológica; um imediato senso de significação do mundo social que, como instrumento por excelência de integração social, torna, pois, possível a construção de consensos para reprodução da ordem social. Entretanto, tentativas de imposição de interesses por determinados agentes podem instituir a violência simbólica, imposta via instrumentos de conhecimento e expressão de realidades (BOURDIEU, 1979, p. 79-80).

A imposição da violência simbólica normalmente é não evidente, não explícita, mas sutil e opressiva. A violência simbólica, que é julgada legítima dentro de cada campo e ao ser inerente ao sistema, é exercida com a cumplicidade daquele que sofre - na autoridade do burocrata, na atitude do intelectual - em favor dos agentes dominantes (BOURDIEU; WACQUANT, 1992, p. 167; BOURDIEU, 1996b, p. 275).

As lutas resultam da tendência de todo campo se reproduzir por meio das ilusões (illusio) necessárias ao funcionamento e à manutenção do sistema. A illusio se apresenta como conjuntos de crenças compartilhadas em um campo, que aparecem como desinteressadas, gratuitas. Entretanto, em função das estratégias dos agentes, são ambíguas por serem inspiradas por uma espécie de interesse pelo desinteresse (BOURDIEU, 2004, p. 31). São concepções tacitamente aceitas como evidentes por estarem em consonância com os interesses dos agentes mais bem posicionados no campo (BOURDIEU; WACQUANT, 1992, p. 117). A illusio é o produto não consciente da adesão à doxa (THIRY-CHERQUES, 2006, p. 39). 
A doxa se constitui no agregado de pressuposições que os antagonistas consideram como autoevidentes, logo, deixam de ser objetos de argumentação, porque constituem a condição tácita do argumento; ou, ainda, a cristalização de questões, muitas vezes incongruentes entre si, que se mantém fora das discussões entre os agentes, em situação de não pensamento. Dependendo do grau de autonomia de dado campo em relação a determinações externas, a arbitrariedade social, em maior ou menor extensão, pode configurar um sistema de pressuposições instituídas como crenças no campo em questão. No mundo social, a doxa pode ser representada por discursos que visam à formação de consenso quanto à existência e à significação de coisas: o senso comum. "É o consenso quanto aos objetos de dissensos" (BOURDIEU, 1975, p. 34; 1996a, p. 21; 1999, p. 339).

\subsection{Relações conformativas e competitivas entre agentes em campos}

$\mathrm{Na}$ definição da estrutura social por meio da alocação de capitais intercambiáveis entre si, cada campo que se constitui se torna lugar de competição mais ou menos público para conservação ou transformação de sua estrutura (BOURDIEU, 1975, p. 23). Como decorrência da posse de capitais distribuídos no campo, os agentes se posicionam de acordo com o volume que detêm em relação à posse dos demais agentes. Entretanto, todos atuam sob pressões da estrutura que são impostas tão mais brutalmente quanto o peso relativo do agente seja, em termos de posse de capitais, menor (BOURDIEU, 2004, p. 24).

A competição viabilizada pela utilização do poder simbólico dos agentes que nunca é completamente independente da posição de cada um - tem por finalidade a definição dos princípios legítimos da divisão do campo. A legitimidade resulta da possibilidade de questionamentos, de ruptura com a doxa que atribui certeza à ordem ordinária, por constituir um senso comum sobre o que todos os agentes estão de acordo (BOURDIEU, 1985, p. 208).

A posição na estrutura da distribuição de capitais específicos governa as características e as estratégias dos agentes ou instituições por meio de sua avaliação prática ou consciente das possibilidades objetivas de vantagens. Aqueles em posições dominantes adotam estratégias essencialmente defensivas, projetadas para perpetuarem o status quo, mantendo, assim, os princípios que sustentam sua posição de dominância. Os problemas sociais emergem, portanto, da confrontação entre grupos defensores de sistemas de interesses e teses antagônicas. Na busca de resolução de tais problemas, por meio da quebra do silêncio da doxa para questionamento do não problemático, a escolha do momento e do local dos embates é deixada para iniciativa dos desafiadores ao status quo (BOURDIEU; NICE, 1980, p. 269).

Outro elemento a ser acrescido para a compreensão das relações estratégicas de posicionamento no campo é o fato de que, com base na homologia entre posições, alianças com certa estabilidade no tempo podem ser estabelecidas, não obstante a existência de divergências ou deslocamentos relativamente conscientes. A homologia de posição constitui a base de uma aliança ambígua por meio da qual agentes - por exemplo, culturais -, sob influência de agentes 
dominantes, direcionam seu capital acumulado para oferecer a terceiros dominados os meios de objetivamente constituírem uma visão de mundo com fundamentos em princípios ou teorias explícitas, ou por meio de influências de instrumentos institucionalizados de organizações de representação, tecnologias sociais de mobilização e manifestação, taxionomias jurídicas, etc. (BOURDIEU, 1979, p. 82; 1985, p. 211).

Embora haja tendências de as alianças serem duradouras, elas não podem ser transformadas em propriedades necessárias e intrínsecas de um grupo qualquer. Das propriedades que lhes caracterizam em dado momento em função de seu posicionamento em um espaço social determinado, há emergência de uma situação de oferta de bens e práticas possíveis. Assim, em uma sociedade, a cada momento, um contexto definido a partir de posições sociais se configura, muitas delas mediante relações de homologia, com reflexos em um conjunto de atividades ou de bens, eles próprios relacionalmente definidos (BOURDIEU, 1996b, p. 18).

\section{Conclusão e implicações}

O delineamento teórico traçado permite significativa ampliação das relações entre agentes, estratégias e estruturas sociais, com potenciais de articulá-los com maior proximidade da complexidade que permeia a realidade de diferentes configurações organizacionais, desde as informais até as formais, estruturadas em diferentes capacidades de ação e perspectivas socioespaciais. Há, pois, pela articulação conjunta, a ampliação tanto conceitual quanto do poder explicativo da realidade em que se incorporam. Com isso, abrindo promissoras oportunidades para captar realidades que se pretende expressar por meio do conceito de governança.

No campo dos estudos organizacionais e de articulações de forças sociopolíticas regionais, uma importante implicação dos pressupostos da Teoria da Prática é representada pela possibilidade de concepção da organização como estrutura social condicionante e condicionada pela produção e reprodução de ações estratégicas de agentes ou grupos de agentes nela implexos, ou daqueles situados em contextos mais amplos da sociedade, que sobre ela exercem influências. Esse é o caso, por exemplo, de tentar vincular ações locais a estratégias globais, como no caso da operacionalização dos Objetivos do Milênio, da cultura da paz, etc., instituídos no âmbito das Nações Unidas.

Com o estabelecimento de relações entre indivíduos e estruturas organizacionais se destaca a heurística, viabilizada pela articulação de conceitos como habitus, campo e capital, a partir da prática. Esses conceitos, considerados inter-relacionadamente, permitem a ampliação de focos de análise para contemplar a complexidade relacional interna das organizações ou de espaços geográficos organizados associada aos efeitos complexos de ações estratégicas exercidas ou sofridas de contextos relacionais externos. Nesse ponto surgem, por exemplo, importantes implicações para o estudo de estruturas de governança e de posicionamento de organizações públicas, privadas e do terceiro setor em 
diferentes contextos sociopolíticos espacialmente situados, estruturados sob a lógica de cooperação ou de competição em redes de políticas.

$\mathrm{Na}$ aplicação prática, diante da riqueza da integração conceitual possibilitada pela Teoria da Prática, há expressiva redução de disruptividades para explicar a existência de relacionamentos de diferentes sistemas sociais, tanto na adoção de estratégias tendentes ao consenso e à cooperação quanto a situações em que se instalam dissensos marcados por posições de antagonismo ou de contradição. Isso tudo, sem relegar os diferentes recursos materiais e simbólicos transacionados. Pelo contrário, nas articulações teóricas há amplos espaços para intercambialidade entre recursos materiais ou não materiais envolvidos em diferentes relações estratégicas entre agentes sociais individuais e coletivos.

Há, enfim, abertura de espaço profícuo para inserção de estratégias de agentes e organizações em espaços de articulações políticas. Ampliam-se, por exemplo, possibilidades de compreender melhor, com a inserção das bases teóricoconceituais da Teoria da Prática, a concepção, a execução e a avaliação de políticas públicas com fundamentos em abordagens, como redes sociais e sistemas de governança multinível (vide, por exemplo, PROCOPIUCK; FREY, 2009a; 2009b; FREY; PROCOPIUCK; ROSA, 2010; FREY; PROCOPIUCK; ROSA, 2011).

\section{REFERÊNCIAS}

BATES, Stephen R.; JENKINS, Laura. Teaching and learning ontology and epistemology in political science. Politics, v. 27, n. 1, p. 55-63, 2007.

BLAIKIE, Norman. Approaches to social: inquiry advancing knowledge. 2. ed. Cambridge, MA, EUA: Blackwell Publishers, 2007.

BOURDIEU, Pierre. Intellectual field and creative project. Social Science Information, v. 8, n. 2, p. 89-119, 1969.

BOURDIEU, Pierre. The three forms of theoretical knowledge. Social Science Information, v. 12, n. 1, p. 53-80, fev. 1973.

BOURDIEU, Pierre. The specificity of the scientific field and the social conditions of the progress of reason. Social Science Information, v. 14, n. 6, p.19-47, jan. 1975.

BOURDIEU, Pierre. Outline of a theory of practice. Cambridge, MA, EUA: Cambridge University Press, 1977.

BOURDIEU, Pierre. Symbolic power. Critique of Anthropology, v. 4, n. 13-14, p. 77-85, jan. 1979.

BOURDIEU, Pierre. The social space and the genesis of groups. Social Science Information, v. 24, n. 2, p. 195-220, jun. 1985. 
BOURDIEU, Pierre. Ontologia política de Martin Heidegger. Campinas: Papirus, 1989a.

BOURDIEU, Pierre. Social and symbolic power. Sociological Theory, v. 7, n. 1, p. 7-25, $1989 b$.

BOURDIEU, Pierre. On the family as a realized category. Theory Culture Society, v. 13, n. 3, p. 19-26, ago. 1996a.

BOURDIEU, Pierre. Razões práticas: sobre a teoria da ação. Campinas: Papirus, 1996b. 224 p.

BOURDIEU, Pierre. Scattered Remarks. European Journal of Social Theory, v. 2, n. 3, p. 334-340, ago. 1999.

BOURDIEU, Pierre. Meditações pascalinas. Rio de Janeiro: Bertrand Brasil, 2001. $320 \mathrm{p}$.

BOURDIEU, Pierre. Os usos sociais da ciência: por uma sociologia clínica do campo científico. São Paulo: Editora Unesp, 2004. 86 p.

BOURDIEU, Pierre; NICE, Richard. The production of belief: contribution to an economy of symbolic goods. Media Culture Society, v. 2, n. 3, p. 261-293, jul. 1980.

BOURDIEU, Pierre; WACQUANT, Loïc J. D. An invitation to reflexive sociology. Chicago, IL, USA: University of Chicago Press, 1992. 348 p.

CAINE, Ken J. Bourdieu in the north: practical understanding in natural resource governance. Canadian Journal of Sociology, v. 38, n. 3, p. 333-358, 2013.

DJALO, Abdulah Bubacar; PROCOPIUCK, Mario. Teoria e prática na construção do conhecimento em administração. Revista Eletrônica de Ciência Administrativa, v. 9, n. 1, p. 90-103, maio 2010.

EMIRBAYER, Mustafa. Manifesto for a relational sociology. The American Journal of Sociology, v. 103, n. 2, p. 281, 1997.

EMIRBAYER, Mustafa; WILLIAMS, Eva M. Boudieu and social work. The Social Service Review, v. 79, n. 4, p. 689-724, 2005.

EVERETT, Jeffery. Organizational research and the praxeology of Pierre Bourdieu. Organizational Research Methods, v. 5, n. 1, p. 56, 2002.

FREY, Klaus; PROCOPIUCK, Mario; ROSA, Altair. Policy-oriented city networks in cyberspace: a methodological approach to the understanding of social and political articulations between cities based on the concept of policy web spheres. International Journal of Advanced Pervasive and Ubiquitous Computing, v. 2, n. 1, p. 18-38, jan./mar. 2010. 
FREY, Klaus; PROCOPIUCK, Mario; ROSA, Altair. Policy-oriented city networks in cyberspace. In: FIRMINO, Rodrigo J.; DUARTE, Fabio; ULTRAMARI, Clovis (Org.). ICTs for mobile and ubiquitous urban infrastructures: surveillance, locative media and global networks. Hershey: IGI Global, 2011. p. 24-47.

GALASKIEWICZ, Joseph; WASSERMAN, Stanley. Social network analysis: concepts, methodology, and directions for the 1990s. Sociological Methods Research, v. 22, n. 1, p. 3-22, ago. 1993.

GALASKIEWICZ, Joseph; WASSERMAN, Stanley. Introduction: advances in the social and behavioral sciences from social network analysis. In: WASSERMAN, Stanley; GALASKIEWICZ, Joseph (Org.). Advances in the social and behavioral sciences from social network analysis: research in the social and behavioral sciences. Thousand Oaks, CA, USA: Sage Publications, 1994. p. xi-xvii.

HAMLIN, Cynthia Lins. Realismo crítico: um programa de pesquisa para as ciências sociais. Dados, v. 43, n. 2, p. 373-398, 2000.

HEPP, Rolf-Dieter. The relational thinking of Pierre Bourdieu. The American Journal of Semiotics, v. 22, n. 1-4, p. 55, 2006.

MICHELINI, Juan José. Territorial governance, local initiatives and urban development: the cases of Getafe and Alcázar de San Juan. Boletín de la Asociación de Geógrafos Españoles, v. 54, p. 421-424, 2010.

MUTCH, Alistair; DELBRIDGE, Rick; VENTRESCA, Marc. Situating organizational action: the relational sociology of organizations. Organization, v. 13, n. 5, p. 607625, set. 2006.

NASH, Roy. What is real and what is realism in sociology? Journal for the Theory of Social Behaviour, v. 29, n. 4, p. 445, 1999.

PAINTER, Joe. Governmentality and regional economic strategies. In: HILLIER, Jean; ROOKSBY, Emma (Org.). Habitus: a sense of place. Aldershot: Ashgate, 2005. p. 131-157.

POTTER, Garry. For Bourdieu, against Alexander: reality and reduction. Journal for the Theory of Social Behaviour, v. 30, n. 2, p. 229, 2000.

PROCOPIUCK, Mario. Políticas públicas e fundamentos da administração pública: análise e avaliação: governança e redes de políticas, administração judiciária. São Paulo: Atlas, 2013. 383 p.

PROCOPIUCK, Mario; FREY, Klaus. Articulações organizacionais em redes de políticas públicas no ciberespaço: o caso da política de difusão social de TICS em Porto Alegre e Curitiba. Revista Organizações \& Sociedade, v. 16, n. 51, p. 687706, out./dez. 2009a. 
PROCOPIUCK, Mario; FREY, Klaus. Redes de políticas públicas e de governança e sua análise a partir da websphere analysis. Revista de Sociologia e Política, v. 17, n. 34, p. 131-144, 2009b.

RIVOLIN, Umberto Janin et al. Towards better territorial governance in europe. Luxembourg: ESPON \& Politecnico di Torino, 2014. 35 p.

ROSA, Altair et al. Redes sociotécnicas no ciberespaço: possibilidades de avaliação de relações sociopolíticas sobre a Agenda 21 e desenvolvimento sustentável local numa policy websphere. In: ENANPUR: PLANEJAMENTO E GESTÃO DO TERRITÓRIO: ESCALAS, CONFLITOS E INCERTEZAS, 13., 25-29 maio 2009. Florianópolis: ANPUR-Associação Nacional de Pós-graduação e Pesquisa em Planejamento Urbano e Regional, 2009.

SAVAGE, Mike. The lost urban sociology of Pierre Bourdieu. In: BRIDGE, Gary; WATSON, Sophie (Org.). The new blackwell companion to the city. Oxford: Blackwell, 2011. p. 511-520.

THIRY-CHERQUES, Hermano Roberto. Pierre Bourdieu: a teoria na prática. Revista de Administração Púbica, v. 40, n. 1, p. 27-55, 2006.

WACQUANT, Loïc J. D. Seguindo Pierre Bourdieu no campo. Revista de Sociologia e Política, v. 26, p. 13-29, 2006.

WALKER, Michael E.; WASSERMAN, Stanley; WELLMAN, Barry. Statistical models for social support networks. Sociological Methods Research, v. 22, n. 1, p. 71-98, ago. 1993.

WASSERMAN, Stanley; FAUST, Katherine. Social network analysis: methods and applications. Cambridge, MA, EUA: University Press, 1997. 825 p.

Sobre o autor Mario Procopiuck

Professor do Programa de Pós-graduação em Gestão Urbana da Pontifícia Universidade Católica do Paraná, Doutor em Administração e Mestre em Gestão Urbana.

Endereço: Avenida Anita Garibaldi, 888, Ahu. 80540180 - Curitiba, PR - Brasil.

E-mail: mario.p@pucpr.br 